\title{
TI.43.1
}

\section{1st Annual PKI Research Workshop Proceedings}

- PDF: proceedings.pdf

\section{More Information}

\begin{tabular}{|l|l|}
\hline Repository ID & TI.43.1 \\
\hline Persistent URL & http://doi.org/10.26869/TI.43.1 \\
\hline Title & 1st Annual PKI Research Workshop Proceedings \\
\hline Authors & Ken Klingenstein, Sean Smith, et al \\
\hline Sponsor & NIST, NIH, Internet2 \\
\hline Review & \\
\hline Status & Legacy \\
\hline Publish Date & August, 2002 \\
\hline DOI & $10.26869 / T I .43 .1$ \\
\hline Signature & \\
\hline Deprecated & No \\
\hline Future Review & \\
\hline Supersedes & \\
\hline Format & PDF \\
\hline Related Docs & \\
\hline Development Location & \\
\hline IP Framework & \\
\hline Subject Tags & \\
\hline Notes & \\
\hline
\end{tabular}

